\title{
As ILHAS CANÁRIAS: PORTO ESTRATÉGICO NAS MOBILIDADES E TRANSFERÊNCIAS PORTUGUESAS DURANTE A CONSOLIDAÇÃO DO MUNDO ATLÂNTICO
}

CANARY ISLANDS: ESTRATEGIC PORT IN PORTUGUESE MOBILITIES AND TRANSFERENCES DURING THE CONSOLIDATION OF THE ATLANTIC WORLD

Javier Luis Álvarez Santos* javisan@ull.edu.es

RESUMO: O objetivo desta publicação é dar a conhecer as características das relações canárioportuguesas no contexto da União Ibérica. Neste contexto, analisaremos primeiramente os antecedentes destes contactos, depois inquiriremos sobre a relevância do contingente português na sociedade canária e, em particular, sobre os vínculos mercantis que se estabelecem entre este arquipélago e os diversos territórios portugueses do Atlântico. Por último, exporemos as repercussões que teve, em Canárias, a Restauração de 1640.

PALAVRAS-ChAVE: Canárias, Portugal, Atlântico.

ABSTRACT: The aim of this paper is to present the characteristics of the Canary-Portuguese relations in the context of the Iberian Union. In this context, this research focuses on the background of these contacts, the relevance of the Portuguese contingent in the Canarian society and, in particular, on the commercial ties established between the archipelago and the Portuguese Atlantic territories. Finally, we discuss the impact of the Restoration in 1640 in the Canary Islands.

KEYWORDS: Canary Islands, Portugal, Atlantic.

\section{Introdução}

A historiografia espanhola, e em especial a canária, tem evidenciado a importância dos europeus na colonização do Arquipélago, tanto no seu povoamento e começo de exploração como no desenvolvimento de relações mercantis. Na verdade, estas actividades comerciais assumiram particular relevância em Canárias e estiveram, em grande parte, nas mãos de estangeiros. Esta integração das ilhas no mundo atlântico implicaram o estabelecimento de indivíduos procedentes de diferentes regiões europeias, que formaram grupos de diferentes magnitudes e níveis de enraizamento. Portanto, é clara a relevância da participação estrangeira na formação da sociedade canária moderna, tanto a nível social como cultural. Do mesmo modo, é hoje reconhecido o importante papel que alguns desses não castelhanos, como os portugueses, tiveram na inclusão das ilhas nos grandes circuitos mercantis. Um fenómeno que foi propiciado pela situação estratégica das Canárias nas rotas circum-atlânticas.

Para levar a cabo esta investigação, estudámos as principais fontes primárias conservadas em Canárias. É de destacar a documentação notarial, conservada no Archivo

\footnotetext{
* Doctor en Historia con mención internacional por la Universidad de La Laguna y por la Universidad Nova de Lisboa.
}

Hist. R., Goiânia, v. 21, n. 3, p. 47-65, set./dez. 2016 
Histórico Pronvincial de Santa Cruz de Tenerife, pela sua contribuição para o conhecimento das actividades económicas, tanto a nível local como ao nível das transações internacionais. Por esta razão, seleccionámos como corpus um conjunto de documentação existente nos principais notários da ilha Tenerife, com o propósito de analisarmos a realidade vivida em determinados períodos-chave nos três principais núcleos populacionais insulares: a capital, a cidade da La Laguna; e os dois portos mais representativos do comércio exterior, que se localizavam em Garachico e La Orotava.

Pela magnitude da documentação, optámos por centrar a nossa atenção em algumas datas, respeitantes a anos anteriores e posteriores à União Ibérica, como foram 1575, 1576 e 1650. Isto, para compreendermos como este acontecimento implicou uma mudança significativa nas relações canário-portuguesas. Os anos da união analisados correspondem a datas em que se registaram ocorrências que alteraram significativamente as relações canárioportuguesas: 1587, 1588, 1603, 1604, 1625 e 1626 . Verificamos, por exemplo, que, enquanto nos primeiros anos o fornecimento de vinhos dos navios da Armada Invencível que se encontrava em Lisboa provinha de Canárias, nos começos do século XVII, devido aos surtos de peste verificados no arquipélago, os contactos com o exterior da llha ficaram bem mais limitados. Por sua vez, a ordem da Inquisição de 1626 para a realização de um censo de portugueses em Canárias permite-nos concluir do crescente volume deste contingente populacional que toma assento no Arquipélago.

\section{Antecedentes}

A presença portuguesa em Castela durante a Idade Moderna tem sido insuficientemente tratada na historiografia espanhola recente. Continua sendo a obra de Domínguez Ortiz, divulgada nos anos sessenta do século passado, a única que, com carácter geral, tratou a questão da presença estrangeira, e especialmente a portuguesa, nos domínios hispânicos (DOMINGUEZ ORTIZ, 1996 [1960]).

O comércio com Portugal tem sido estudado e os raros trabalhos produzidos neste âmbito ocupam-se, sobretudo - mas apenas -, do comércio de escravos (OTTE; RUÍZBARRUECOS, 1963; VILA VILAR, 1979; GARCÍA FUENTES, 1982) e da penetração lusitana no comércio com as Índias (COLLADO VILLALTA, 1979; SERRANO MANGAS, 2001; LÓPEZ BELINCHÓN, 2001). Contudo, nas últimas décadas do século $X X$, alguns historiadores 
começaram já a ocupar-se de outros aspectos das relações com Portugal, dando especial atenção ao período da União Ibérica.

Assim, no âmbito da História Política, destacam-se os trabalhos de Bouza Álvarez (1987; 1997; 2000), Luxán Méndez (1988), Valladares Ramírez (1994; 1998) e Cardim (2004), entre outros. Boyajian (1983) e Ebben (1993; 1996) estudaram o papel dos banqueiros portugueses no financiamento da Monarquia Hispânica. Outros autores têm ainda analisado o desempenho dos judeus convertidos nas finanças e no desenvolvimento de redes comerciais internacionais, particularmente durante a privança do Conde Duque de Olivares (BROENS, 1989; CARRASCO VÁZQUEZ, 1997; 2001; 2004; CONTRERAS CONTRERAS; GARCÍA GARCÍA; PULIDO SERRANO, 2002; VALLADARES RAMÍREZ, 2002). E para além destes trabalhos, há ainda alguns historiadores que começam a situar as relações hispáno-portuguesas, e a própria história das ilhas ibérias do Atlântico, no enquadramento teórico e historiográfico da História Atlântica (ELLIOTT, 2001; VALLADARES RAMÍREZ, 2006; VIEIRA, 2002).

Foram numerosas as investigações que se dedicaram ao estudo dos grupos de europeus em Canárias, quase sempre sob a forma de trabalhos específicos sobre determinadas comunidades. Assim, destacam-se os ensaios a respeito da presença de italianos, designadamente de genoveses; de flamengos e dos laços que estes estabeleceram entre Canárias e o norte da Europa; bem como da presença de ingleses, franceses, ou irlandeses no arquipélago (MARRERO RODRÍGUEZ, 1950; ASÍN; VIÑA BRITO, 2004; FAJARDO SPÍNOLA, 1996; LOBO CABRERA, 1987; GUIMERÁ RAVINA, 1985). No entanto, esses trabalhos sempre têm centrado as suas atenções apenas em determinadas ilhas e/ou determinados períodos, sendo escassas as publicações que tratem esta questão de uma maneira mais abrangente.

De entre os europeus que chegaram a Canárias, mesmo antes de serem conquistadas as ilhas centrais que passariam a ser pertença do rei, destacam-se os portugueses. Porém, a importância do elemento português no arquipélago será abordada pela primeira vez na historiografia recente por Serra Ráfols, Catedrático de História e professor de Literatura Portuguesa da Universidade de La Laguna, e apenas no discurso inaugural do ano académico 1941-1942 (SERRA RÁFOLS, 1941). Uma década mais tarde, seria Pérez Vidal quem, no seu liminal trabalho sobre a influência lusa na língua, na cultura tradicional e nos ofícios, 
destacaria também a relevância dessa presença no arquipélago (PÉREZ VIDAL, 1991) ${ }^{1}$. Questões relacionadas com as relações humanas e a demografia viriam a ser tratadas, por seu lado, em duas importantes publicações (PÉREZ VIDAL, 1968): a primeira delas de Bonnet y Suárez, centrada na análise do estabelecimento de portugueses na cidade de La Laguna, a partir de um censo da Inquisição (BONNET SUÁREZ, 1951); a segunda, de Fajardo Spínola publicada mais de cinquenta anos depois da primeira (FAJARDO SPÍNOLA, 2004), onde se estudam as motivações que levaram a Inquisição a proceder a esse registo demográfico e onde são apresentadas, a este respeito, novas interpretações dos dados então recolhidos.

No entanto, as relações comerciais, sobretudo com os arquipélagos de Açores e Madeira, constituíram a temática que, com maior acuidade, atraiu o interesse dos investigadores. Em Canárias, destacam-se os trabalhos comparativos de Lobo Cabrera (1985, 1990) e Torres Santana (1996). Por seu lado, em Portugal, os historiadores centraram-se no estudo dos arquipélagos num contexto mais amplo, partindo da sua situação geográfica no Atlântico (MATOS, 1985). A este respeito, importa sublinhar a relevância dos trabalhos de Alberto Vieira $(1987 ; 1991 ; 1992 ; 2001 ; 2004)$.

\section{Espaço das ilhas}

O arquipélago canário é constituído por sete ilhas principais. Ao contrário das ilhas portuguesas da Madeira e dos Açores, em Canárias existia uma população de origem norteafricana, prévia à chegada dos europeus ${ }^{2}$. Essa sociedade pré-hispânica conseguiu dominar o território, opondo resistência às diferentes tentativas de conquista, circunstância que determinou que a incorporação de cada uma das ilhas se realizasse em momentos diferentes, alongando-se no tempo, até quase um século de diferença entre a primeira e a última conquista ${ }^{3}$.

No entanto, a incorporação das ilhas nos domínios de Castela, verificada no fim do século XV, correspondeu, na verdade, ao findar de uma disputa anterior entre potências

\footnotetext{
${ }^{1}$ Seus artigos foram posteriormente publicados em um único volume.

${ }^{2}$ Antonio Tejera Gaspar (2006, p. 81), catedrático de Arqueología da Universidad de La Laguna, não duvida em afirmar que: "Sabemos ciertamente que los aborígenes canarios están emparentados con poblaciones norteafricanas, las gentes que los griegos conocieron como libios y, con posterioridad los romanos como bereberes [...]".

${ }^{3} \mathrm{O}$ processo de conquista inicia-se com a empresa dos normandos, comandada por Jean de Bethencourt e Gadifer de la Salle, sobre a ilha de Lanzarote e culminará em 1496 na incorporação de Tenerife e La Palma na mão do Adiantado Alonso Fernández de Lugo.
} 
europeias, uma vez que o domínio dos arquipélagos supunha o controlo definitivo do Atlântico e a garantia da expansão atlântica. Nesta disputa, participaram os normandos, desde começos do Quatrocentos, mas também tiveram interesses nesta empresa os maiorquinos, andaluzes, genovêses e pisanos. No entanto, serão Portugal e Castela as coroas que disputarão o domínio definitivo de Canárias. Não esqueçamos as aspirações portuguesas ao continente africano, pelo que o controlo do Arquipélago seria fundamental para a concretização dos interesses lusos. É provável que em 1415 Portugal tivesse atingido, pela primeira vez, a ilha de Gran Canaria, por via de uma expedição da armada do Infante D. Henrique (SERRA RÁFOLS, 1941, p. 21), antecipando, assim, a tentativa de conquista de 1424, comandada por D. Fernando de Castro (PÉREZ VIDAL, 1991, p. 15).

No entanto, o acordo de paz de Alcaçovas entre Portugal e Castela supôs o fim das hostilidades no Atlântico, levando a segunda a abandonar as suas pretensões na costa africana para além de Canárias, enquanto o primeiro renunciava aos seus direitos sobre este Arquipélago (PÉREZ VIDAL, 1991, p. 19).

Com a incorporação de Canárias na coroa de Castela, instauraram-se nas ilhas modelos administrativos medievais europeus, desaparecendo as estruturas socioeconômicas aborígines anteriores. Por um lado, em Lanzarote, Fuerteventura, La Gomera e El Hierro instaura-se um sistema de senhorio. Por outro lado, em La Palma, Tenerife e Gran Canaria estabeleceu-se um sistema de realengo.

La Palma, Tenerife e Gran Canaria constituem, assim, o núcleo de ilhas que irão impulsionar as principais actividades económicas, centradas particularmente em produtos de exportação, como fossem o açúcar e o vinho. Enquanto isso, as ilhas orientais de Lanzarote e Fuerteventura converter-se-ão no celeiro de Canárias, fornecendo frequentemente às ilhas de realengo, para a subsistência da população insular. Deste modo, vai-se articulando um sistema de complementaridade no próprio Arquipélago que, por sua vez, está integrado em outro circuito mais amplo, e em que estão integrados também os restantes arquipélagos macaronésicos.

De entre as ilhas de Canárias, Tenerife gerará o maior número de negócios, convertendo-se numa praça mercantil internacional de primeira ordem. Este desenvolvimento comercial encontra-se motivado pelo rápido estabelecimento de uma economia baseada no cultivo exportador. Depois da Conquista, promove-se o trabalho da 
cana-de-açúcar, passando esta a ser cultura predominante e o principal produto canário procurado pelos mercados exteriores.

No entanto, a partir das últimas décadas do século XVI - período que coincide com o início da União Ibérica - assiste-se ao declínio do comércio deste produto, devido, fundamentalmente, à concorrência do açúcar brasileiro nos mercados europeus, que aqui registava um preço muito mais baixo. No entanto, este cultivo exportador foi rapidamente substituído por outro: a videira. Não se tratava, de facto, de algo novo, pois o vinho já era produzido nas ilhas para abastecimento dos próprios ilhéus. Na verdade, a crise do açúcar apenas impulsionará a produção vinícula, transformando o vinho no novo produto exportador.

\section{Canárias e o seu meio geográfico}

O mundo insular macaronésico sempre tem estado presente nos estudos atlânticos. Desde a Antiguidade que se registam notícias relativas à existência de umas ilhas situadas no Atlântico, notícias estas responsáveis pela construção de múltiplas utopias. Este anseio por encontrar novas fronteiras teve o seu momento culminante durante o período dos Descobrimentos.

Neste contexto, Canárias foi a principal porta de acesso da Europa ao Novo Mundo, funcionando como ponto de escala fundamental na rota para a América tropical. No retorno, era aos Açores que cabia esse papel, dado que as condições de navegação à vela no Atlântico obrigavam a uma escala nestas ilhas. Contudo, foram também razões económicas - e não apenas de técnica de navegação - que determinaram a relevância de Canárias no âmbito da rota para o Novo Mundo: a permanência das naus nos arquipélagos permitia o intercâmbio de mercadorias, e assim, os insulares demandavam produtos estrangeiros para o consumo interno, ao mesmo tempo que comercializavam os seus excedentes no mercado exterior.

Neste sentido, aplicou-se um modelo económico para Canárias muito semelhante ao existente no resto das ilhas macaronésias, caracterizado pelo seguinte: uma máxima potenciação das economias de escala; o equilíbrio entre os recursos agrícolas destinados ao consumo interno e os comercializados; a complementaridade entre ilhas exportadoras e fornecedores mediante a estruturação do mercado regional; e a minimização de custos e 
riscos com a diversificação e especialização económica entre arquipélagos ao longo dos séculos XVI e XVII (GUIMERÁ RAVINA; VIEIRA, 1996, p. 206).

Deste modo, o Oceano converte-se no eixo regulatório das relações entre estes espaços insulares. O Atlântico vai adquirindo, durante a Idade Moderna, o mesmo papel estrutural que até então o Medierrâneo tinha assumido, como um mar interior que coloca em articulação, em relação e em comunicação diferentes regiões. Desde então, ter-se-ia forjado um vínculo entre as orlas do Oceano, por via de uma mediação direta das Ilhas, as quais assumem uma função estratégica nas rotas de navegação, bem como na circulação de pessoas e produtos.

Assim, tanto a historiografia espanhola que se ocupou do estudo do Novo Mundo, como os estudos atlânticos portugueses enfatizaram o valor dos espaços insulares nos intercâmbios trans-oceânicos, sublinhando, de igual modo, a relevância que, para o desenvolvimento desses intercâmbios, assumiram quer as relações de concorrência e complementaridade inter-ilhas, quer outro tipo de relações não convencionais e de carácter sócio-cultural ou até familiar4.

\section{Contexto económico de Canárias}

A economia canária durante esta época - final do século XVI até meados do próximo século - deve ser entendida no contexto da crise geral vivida na Europa deste período, já que as actividades comerciais que, então, aí se desenvolvem se centram no Atlântico, na rede mercantil europeia, intensa e diversificada, que aí se desenvolve.

Desde meados do século XVI, Canárias já tinha quebrado os laços de dependência económica com Castela e o Mediterrâneo, em favor do Atlântico. A exploração da cana-deaçúcar durante a época de Quinhentos, e sobretudo com o desenvolvimento da produção de vinho durante a primeira metade do século XVII, poriam fim à complementaridade económica estabelecida entre Canárias e sua metrópole. Os comerciantes do vinho assentados nas Ilhas, entre eles os portugueses, potenciariam a demanda nos mercados tanto europeus como coloniais. Por sua vez, os portos canários converter-se-iam numa das mais relevantes bases das operações comerciais atlânticas, grande parte delas ilícitas.

\footnotetext{
"Uma trilogia clássica para a historiografia "americanista" canária sobre o comércio internacional CanáriasAmérica: Morales Padrón (1955), Pereza de Ayala (1977) e Rumeu de Armas (1991).
} 
Tudo isto decorrerá do receio dos comerciantes de Sevilha, com voz na Casa de Contratação, e da consequente imposição de medidas restritivas por parte das autoridades peninsulares. A singularidade mercantil de Canárias criará, assim, uma brecha no monopólio castelhano, ao mesmo tempo que competia directamente com os vinhos da Andaluzia, estes transaccionados com preços mais baixos e com menores custos de venda.

Assim, para controlar a oferta insular, estabeleceram-se, entre os anos 1566 e 1657, os juízes de registo nos portos canários, tendo-se ainda proibido a navegação fora das frotas reais e limitado a tonelagem dos produtos a exportar. Restringida a possibilidade de remeter mercadorias para as Índias, os comerciantes canários procuraram outras alternativas, principalmente no Império ultramarino português (BETHENCOURT MASSIEU, 1977, p. 267). Deste modo, Canárias converter-se-á numa plataforma estratégica para os intercâmbios mercantis entre Portugal e seus territórios no ultramar, redistribuindo os produtos brasileiros e africanos para a Europa, ao mesmo tempo que aí se adquiria o vinho canário e se comercializavam produtos estrangeiros que faziam escala nas llhas.

A chegada destas embarcações lusas atraiu a atenção de outros mercadores europeus interessados neste frutífero mercado, chegando mesmo, em certas ocasiões, a acompanhar os navios portugueses. Contudo, a proibição de comerciar com alguns territórios implicou que numerosos mercadores europeus financiassem de maneira ilegal estas empresas através de agentes portugueses.

Note-se que, neste contexto atlântico, as Canárias participam em três rotas mercantis principais. A primeira delas seria a estabelecida pelo monopólio da Coroa, partindo de Sevilha, fazendo escala no Arquipélago para carregar fornecimentos, e continuando, depois, para as Índias. Do Velho Continente chegavam produtos manufacturados, que depois seriam reexportados para a América, já que a quantidade remetida para o Arquipélago era superior à necessária para a população local.

O segundo roteiro ligaria Canárias à África e à América. Do Arquipélago partiam embarcações para Cabo Verde, Guiné, ou Angola, carregadas com os vinhos canários em busca de escravos. Daí, regressavam às Ilhas para vender parte dos escravos em troca de novos vinhos e continuavam a viagem para a América. Devemos lembrar que, apesar da união entre Castela e Portugal, os portugueses continuavam sendo os únicos proprietários dos assentos concedidos pela Coroa. 
E, por fim, havia ainda a rota que ligava Canárias à Península Ibérica e à Europa. Será por esta via que o Arquipélago se abastecerá de produtos elaborados, em contínua demanda nos portos europeus, para satisfazer as necessidades dos insulares. Por exemplo, madeiras procedentes de Portugal para a fabricação canária de pipas.

\section{As Ilhas do Oceano}

Esta multiplicidade de rotas foi o resultado dos intercâmbios entre as áreas insulares e continentais. Mas estas particularidades devem ser entendidas dentro do meio geográfico circum-atlântico, já que as correntes e ventos delinearam o traçado das viagens para o Novo Mundo.

Deste modo, os itinerários portugueses e castelhanos apresentavam um percurso bem diferente. Enquanto os primeiros partiam de Lisboa e Porto, os castelhanos saíam de Sevilha com destino às Índias Ocidentais, tendo, nessa rota, como pontos estratégicos, os arquipélagos de Canárias e Açores. Esta última escala, a açoriana, justificava-se mais pela necessidade de proteção pelas armadas da Coroa, dos navios que transportavam a prata e o ouro na volta da América, do que pela necessidade de abastecimento ou conserto das embarcações. Pelo contrário, a implicação do arquipélago madeirense nas grandes rotas atlânticas foi ocasional, entendendo-se esta ausência pela sua posição marginal no trajeto natural. No entanto, a Madeira não foi alheia a esses trânsitos e em diversas ocasiões serviu também como escala para o fornecimento de vinho para consumo dos tripulantes, em viagens com destino ao Brasil e Guiné.

A consolidação destas escalas de abastecimento acelerou a expansão dos contactos mercantis entre os três arquipélagos, já que o comércio entre estes se associou ao intercâmbio de produtos específicos. Os madeirenses tinham para oferecer aos Açores: vinho, açúcar ou produtos fabricados na Europa. Enquanto isso, Canárias oferecia frutos e tecidos. Por sua vez, as ilhas açorianas forneciam cereais às outras duas regiões, ao mesmo tempo que se convertiam em consumidoras principais do vinho madeirense e canário.

Importa salientar que estes contactos comerciais surgem simultaneamente como consequência - e causa - das migrações humanas. Desde fins do século XVI, o arquipélago castelhano é o primeiro destino da emigração madeirense. Esta acentuada presença da Madeira no arquipélago vizinho foi o resultado das possibilidades económicas que Canárias 
oferecia, bem como da demanda de mão de obra pelos madeirenses e das possibilidades que, a partir do Arquipélago, se apresentavam para a penetração mercantil na costa africana e no continente americano. No entanto, para que esta rede de contactos económicos permanecesse, era necessária a existência de uma comunidade prévia, responsável pelo estabelecimento de vínculos anteriores, capazes de suportar esses intercâmbios.

Para além disto, o contexto da União política facilitou a interação entre Canárias e os territórios portugueses, alargando-se os interesses para outras áreas: antes de tudo, convém notar o triângulo formado por Cabo Verde, Guiné e Angola5; mas também sublinhar a relevância crescente do contacto com o Brasil, devido à localização do Arquipélago no melhor caminho das embarcações desde Lisboa até ao Novo Mundo 6 . Aliás, esta rede de relações pode-se observar na complexa rota do comércio de escravos. Em certas ocasiões, as embarcações portuguesas abasteciam-se de vinho canário antes de partir para o continente africano, ao mesmo tempo que muitos destes barcos negreiros desembarcavam em Canárias antes de continuar para a América, aproveitando para deixar parte da mercadoria requerida pelo mercado insular.

\section{A presença portuguesa nas Canárias}

A relevância da comunidade lusa numa ilha como Tenerife, desde a sua incorporação na coroa de Castela, tem gerado um interessante debate na historiografia canária ${ }^{7}$. E hoje é tido como certo que a necessidade de um rápido repovoamento teria facilitado a integração

\footnotetext{
${ }^{5}$ Em 1625, Álvaro González Gransses, vizinho de Cacheo na Guiné, deu crédito por 2000 ducados em diversas letras a Pascual de Deita, vizinho de Santiago de Cabo Verde e capitão da caravela San Antonio. Estas letras seriam pagas a Luis Rodríguez de Acuña, em Lisboa. Implicavam ainda que tivesse de passar em Canárias e carregar tantas pipas de vinho como pudesse. ARCHIVO HISTÓRICO PROVINCIAL DE SANTA CRUZ DE TENERIFE [AHPSCT], Protocolos notariales, no 2278, fl. 358v (Escribanía de Gaspar Delgadillo, Garachico, 27 de Agosto de 1625).

${ }^{6}$ Um exemplo, encontramo-lo no contrato de fretamento realizado em 1626 entre o dono de navio português e o vereador da ilha de Tenerife, também de origem postuguesa, Luis Lorenzo. Neste acordo estipula-se que uma vez chegada a embarcação ao Brasil, a sua carga seria entregue, provavelmente composta em parte por pipas de vinho das Canárias. A embarcação seria uma vez mais carregada com caixas de açúcar que seriam vendidas em Lisboa. Neste trato, o consignatário obtinha dois terços dos ganhos e o senhor da embarcação o terço restante. ARCHIVO HISTÓRICO PROVINCIAL DE SANTA CRUZ DE TENERIFE [AHPSCT], Protocolos notariales, no 2279, fl. 792 (Escribanía de Gaspar Delgadillo, Garachico, 18 de Setembro de 1626).

${ }^{7}$ Referimo-nos aos trabalhos publicados nos anos oitenta do século passado por Verlinden (1987), FernándezArmesto (1996) e Aznar Vallejo (1983). Enquanto estes dois últimos historiadores, a partir das investigações que realizam para as datas de distribuição de terras e os testamentos, acentuam a importância numérica dos povoadores portugueses, acima dos próprios castelhanos. Por sua vez, Charles Verlinden desconfia dos dados estatísticos e defende uma integração mais matizada na nova sociedade insular, já que, embora o propósito inicial destes primeiros colonos fosse povoar o território, nem todos aí permaneceriam.
} 
deste contingente na incipiente sociedade insular. Assim, os portugueses teriam beneficiado da partilha das terras da Ilha e, de igual modo, teriam participado activamente quer na implantação da cultura da cana-de-açúcar, quer, depois, no desenvolvimento do processo de exportação deste produto (BELLO LEÓN, 1998). Daí não surpreender a presença marcante da comunidade portuguesa na sociedade e na economia insular, bem como a sua intensificação durante grande parte da Idade Moderna, pelo menos até meados de Seiscentos.

Por outro lado, é claro que a população portuguesa é uma dos grupos não castelhanos mais numerosos. Deste modo, enquanto outros contingentes estrangeiros destacados, como sejam os genoveses e flamengos, deixarão de actuar em Canárias, os naturais de Portugal vão-se adaptando a cada nova conjuntura, consolidando a sua presença com o passar dos séculos. Em proporção, os portugueses já eram maioritários relativamente a outros estrangeiros, desde períodos anteriores ao da União Ibérica, vindo o seu número a crescer gradualmente, até atingir o seu auge durante o primeiro quarto do século XVII.

Esta preponderância é consequência do estabelecimento de redes sócio-económicas instituídas tanto na Europa como na América, fazendo com que as suas acções em Canárias fossem notáveis e contínuas no tempo. Por sua vez, a sociedade insular permitirá este nível de integração da população portuguesa, devido, é certo, à proximidade linguística e cultural, mas sobretudo por, através destas relações, poder tirar partido de outras oportunidades de negócio.

Não se trata, portanto, de um contingente hermético, dedicado exclusivamente ao comércio exterior, como se verificava com os ingleses. Os portugueses, na verdade, participavam em todas as actividades produtivas que se desenvolviam na Ilha: agricultura, navegação, ofícios artesanais e comércio. Para além disto, eram também membros destacados da sociedade, estabelecendo relações familiares com a oligarquia terratenente local e ocupando mesmo cargos públicos, tais como almoxarifes ou membros da câmara, com o propósito de participar no controle económico insular. Verificamos, assim, que a comunidade lusa estabeleceu uma próspera rede sócio-económica, efectivamente adaptada às evoluções e transformações conjunturais, facto que determinou que não se registassem, ao longo do tempo, significativas variações nessa mesma comunidade, quer em termos quantitativos ou qualitativos. 
A historiografia canária justificou a relevância das populações estrangeiras no arquipélago através da capacidade mercantil que eram capazes de assumir a partir de um determinado negócio que as tivesse levado até Canárias. Seria a partir daqui que se desenvolveria todo o seu potencial económico até que, por um novo acontecimento, a empresa a que se haviam dedicado deixasse de ser rentável e, dadas essas circunstâncias, os elementos dessa comunidade estrangeira decidissem abandonar as Ilhas. Porém, convém aqui destacar que, diferentemente dos restantes grupos, os portugueses, graças à sua capacidade de adaptação, permaneceram estáveis no Arquipélago durante um século e meio.

\section{As relações comerciais entre Canárias e Portugal}

As transações que os mercadores portugueses estabelecidos em Canárias realizavam não devem ser entendidas unicamente numa perspetiva local, mas antes num contexto bem mais amplo e dinâmico. Ao longo desta exposição, por diversas vezes se fez referência aos produtos transaccionados entre Canárias e os territórios portugueses. Neste sentido, não restam dúvidas que o vinho insular foi o produto mais demandado pelas praças lusas, assim como pelos demais mercados europeus.

É de notar, por exemplo, como certos poderes notariais se outorgam para cobrar, em Portugal, pipas que foram remetidas anteriormente. Nos documentos compulsados, é frequente a existência de divergências quanto à procedência dos outorgantes, sendo estes apresentados ora como canários, ora como sevilhanos, genoveses, franceses, flamengos ou alemães. Pelo contrário, os que recebem o poder são, na sua maioria, vimaranenses, portuenses e lisboetas ${ }^{8}$.

O comércio com o exterior ajudou o abastecimento da população local no que diz respeito a outras mercadorias, favorecendo ainda o investimento em outros negócios. Não obstante, outros géneros houve que, em menor medida, também se exportaram: o trigo, o açúcar, a breu, os tecidos ou as especiarias. Em resultado destas transações, as importações de produtos lusos para Canárias foram muito diversas, variando de acordo com sua procedência.

\footnotetext{
${ }^{8} \mathrm{Em} 1587$, Pascual de Palos, vizinho de Vila do Conde, deu poder para cobrar uma letra pelo valor de umas pipas de vinho que haviam sido remetidas desde o porto de Garachico. ARCHIVO HISTÓRICO PROVINCIAL DE SANTA CRUZ DE TENERIFE [AHPSCT], Protocolos notariales, no 669, fl 149 (Escribanía de Lucas Rodríguez Sarmiento, Garachico, 30 de Abril de 1587).
} 
Assim, dos Açores se traficava o trigo, sobretudo em momentos de maior escassez nas ilhas castelhanas. Por outro lado, do Reino embarcavam-se diferentes produtos artesanais, de entre os quais cabe destacar as varas, os tecidos e os vestidos. Mais lucrativo foi o tráfico de escravos nas mãos de portugueses durante toda a União Ibérica, por serem eles os únicos autorizados pela Coroa a fazerem-no. Os seus traficantes eram na sua maior parte portugueses do Reino ou agentes procedentes de Cabo Verde, que traficavam com pessoas dotadas de verdadeiro poder de compra, como comerciantes, vereadores, escrivãos ou religiosos (LOBO CABERA, 1998, p. 62) ${ }^{9}$. Este comércio, segundo se depreende da documentação consultada, tendeu para uma evolução ascendente, conforme decorria o século XVII. Os escravos - na sua maioria, homens a rondar os vinte anos, variando o seu valor segundo a sua origem, sexo e idade - procediam essencialmente de Guiné e Cabo Verde, sendo trocados nos mercados canários pelos angolanos nos começos de Seiscentos.

Neste contexto, os escravos provenientes de Cabo Verde tinham um preço médio de 685 reais, ao mesmo tempo que os guineenses eram cerca de $12 \%$ mais caros, e os escassos índios da América portuguesa chegavam a atingir os 1000 reais. Por sua vez, as mulheres vendiam-se por um preço superior ao dos varões, por volta de $20 \%$ mais caras. A variação de preço era ainda determinada pela idade, verificando-se que o preço dos jovens escravos era superior em cerca de $10 \%$ quando comparado com os valores pagos quando aqueles atingiam a maturidade.

Neste sentido, é de sublinhar a importância do tráfico entre Canárias e o ultramar português, principalmente com Brasil e Cabo Verde, desde meados do século XVI. Um facto documentado, desde logo, pela presença de comerciantes estrangeiros em navios portugueses que chegam às Ilhas ou partem delas para a América. Daí que em 1569 a Coroa exija o registo das embarcações que se dirigem a Cabo Verde e Brasil, através de um decreto real dirigido ao juiz de registro, já que, segundo esta documentação, neles "iban frailes y otras personas sin licencia regia" (MORALES PADRÓN, 1970, p. 102). Uma ordem que será reiterada pelo monarca em sucessivas ocasiões, como consequência das contínuas infrações cometidas nas Ilhas contra esta disposição e de igual forma em resultado das petições remetidas desde

\footnotetext{
${ }^{9}$ Este é o caso Juan de Vega, um importante agente português assentado de Tenerife, procedente de Cabo Verde, encarregado de introduzir escravos no Arquipélago (ÁLVAREZ SANTOS, 2010).
} 
Canárias, o que assinala o volume do tráfico mercantil para esses territórios (VIÑA BRITO, 2007).

No ano de 1601, em plena União Ibérica, proibiu-se, por exemplo, que o governador das ilhas de Tenerife e de La Palma, assim como a câmara municipal de Tenerife, se intrometessem nos assuntos da carga e descarga de navios, como faziam habitualmente. Concretamente, impediu-se que os responsáveis por esses cargos interviessem na visita dos barcos procedentes do Brasil e Cabo Verde. No mesmo ano insistir-se-á outra vez, mediante um novo decreto real, para que os navios com destino ao ultramar português trouxessem registo de volta para evitar que viajassem ilegalmente às Índias (CIORANESCU, 1977, p. 462; LOBO CABRERA; TORRES SANTA, 2000, p. 173).

A importância deste comércio na cojuntura internacional observa-se uma vez mais em 1607, momento em que o juiz de registos de Tenerife chega a questionar sobre se deve consentir a demanda dos vizinhos de Tenerife, os quais requeriam autorização para carregar mercadorias dos barcos franceses, ingleses e holandeses com destino ao Brasil, sem a obrigação de levar registos, uma vez que as autoridades portuárias brasileiras não os exigiam. Mais ainda, o juiz Alonso de Ciancas advertia que, dos benefícios que deixava o arrendamento dos direitos dos almoxarifazgos de 1618, o maior aproveitamento era o proveniente dos navios do Brasil, "porque los de Francia y Flandes son mucho menos en número y los de las Indias, además de ser pocos, sólo pagan un dos y medio por ciento, mientras que los de Brasil pagan el seis por ciento" (VILA VILAR, 1978, p. 286-287).

\section{O fim de uma era}

É verdade que depois da Restauração de 1640 se produz uma ruptura, mas há que enfatizar já que a separação é apenas mais um elemento, dentro de uma série de circunstâncias que resultaram no declínio destas relações de longa duração. E interessa destacar que esta situação coincide, no tempo, com a quebra da economia do vinho, registada em Canárias. Em 1633, tinham-se elevado os impostos com a finalidade de potenciar o vinho português, sobretudo o da Madeira, tendo-se este arquipélago convertido, já nestes anos, em um importante produtor vinícula. Em 1649, ano em que a Coroa proibiu o comércio canárioamericano, constituiu-se a Companhia Brasileira, que limitava, em Canárias, o comércio do vinho e a participação no tráfico de escravos. 
Para esta alteração do contexto atlântico contribui ainda significativamente a emergência de um outro agente que, a partir de então, assumirá uma cada vez maior relevância nas relações transatlânticas. A partir destes anos, a Inglaterra vai converter-se numa das grandes potências marítimas e comerciais, substituindo o domínio hispânico no Atlântico. Esta nova realidade materializa-se com as Actas e Leis de Navegação Inglesas de meados do século XVII. Estas liberalizavam as importações de vinho e especialmente de vinhos portugueses, os quais começaram a substituir a oferta canária no mercado inglês. Mais concretamente, as Actas de Navegação (1663) proibiam o comércio directo dos vinhos canários nas colónias inglesas, favorecendo as exportações madeirenses. Acrece que os ingleses constituíram a Companhia de Canárias em 1666, ficando todo o comércio entre Inglaterra e o Arquipélago nas mãos dos seus membros.

Contudo, esta situação resultou insustentável para os insulares, que se revoltaram em Garachico nesse mesmo ano. No entanto, esta não foi a única situação violenta derivada da crise do vinho. Já em 1648 se registou um outro levantamento contra os mercadores portugueses, considerados responsáveis pela crítica situação por parte dos agitadores.

\section{Considerações finais}

Em sínteses, os vínculos entre Canárias e Portugal existem desde antes da conquista do Arquipélago por Castela, embora fortalecidos durante a União Ibérica. No entanto, não se podem entender estas mobilidades e transferências sem conhecer as circunstâncias económicas e sociais do mundo atlântico. A condição estratégica de Canárias ajudará a articular as redes económicas internacionais. Deste modo, os comerciantes ilhéus e agentes portugueses no Arquipélago participarão activamente nesta rede de conexões sociais e económicas que superam o próprio âmbito local. Para alcançar o máximo proveito desta circunstância, os mercadores lusos desenvolverão um conjunto de relacionamentos que se estenderão de Portugal à América e África, utilizando as ilhas castelhanas como um dos principais mercados para efectuar as transacções comerciais. Nesta conjuntura, as Canárias converter-se-ão em um porto estratégico para os interesses portugueses.

\section{REFERÊNCIAS BIBLIOGRÁFICAS}

ÁLVAREZ SANTOS, Javier Luis. Vínculos en el Atlántico: Juan de Vega, Señor del Ingenio de Güímar. II Jornadas de Historia del Sur de Tenerife. Ayuntamiento de Arona, Arona: 2010, p. 53-67.

ASÍN, Luise; VIÑA BRITO, Ana. La Palma: la herencia de Flandes. La Palma: Cabildo de La Palma, 2004. 
AZNAR VALLEJO, Eduardo. La integración de las Islas Canarias en la Corona de Castilla (1478-1526). Aspectos administrativos, sociales y económicos. Santa Cruz de Tenerife, Espanha: Secretariado de Publicaciones de la Universidad de La Laguna, 1983.

BELLO LEÓN, Juan Manuel. La participación de los extranjeros en los repartimientos canarios. Introducción a su estudio. El Museo Canario, Las Palmas de Gran Canaria, n. 53, p. 187-213, 1998.

BETHENCOURT MASSIEU, Antonio. Canarias y el comercio del vino (siglo XVII). In: MILLARES TORRES, Agustín. (Ed.). Historia General de las Islas Canarias. Edirca. Las Palmas de Gran Canaria, v. 3, 1977. p. 145-180.

BONNET SUÁREZ, Sergio Fernando. Familias portuguesas en La Laguna del siglo XVII. Revista de Historia Canaria, La Laguna, n. 93-94, p. 111-118, 1951.

BOUZA ÁLVAREZ, Fernando. Portugal en la monarquía hispánica (1580-1640): Felipe II, las Cortes de Tomar y la génesis del Portugal católico. Madrid: Universidad Complutense, 1987.

BOUZA ÁLVAREZ, Fernando. De las alteraciones de Beja (1593) a la revuelta lisboeta "dos ingleses" (1596): lucha política en el último Portugal del primer Felipe. Salamanca: Ediciones Universidad de Salamanca, 1997.

BOUZA ÁLVAREZ, Fernando. Portugal no tempo dos Filipes: política, cultura, representações (15801668). Lisboa: Cosmos, 2000.

BOYAJIAN, James C. Portuguese bankers at the court of Spain, 1626-1650. New Brunswick, NJ: Rutgers University Press, 1983.

BROENS, Nicolás. Monarquía y capital mercantil: Felipe IV y las redes comerciales portuguesas (16271635). Madrid: Universidad Autónoma de Madrid, 1989.

CARDIM, Pedro. Los portugueses frente a la Monarquía Hispánica. In: ÁlVAREZ-OSORIO ALVARIÑO, Antonio; GARCÍA GARCÍA, Bernardo. (Ed.). La monarquía de las naciones: patria, nación y naturaleza en la monarquía de España. Madrid: Fundación Carlos de Amberes, 2004. p. 355-384.

CARRASCO VÁZQUEZ, Jesús. Contrabando, moneda y espionaje (el negocio del vellón, 1606-1620). Hispania, n. 197, p. 1081-1105, 1997.

CARRASCO VÁZQUEZ, Jesús. Los judeoconversos portugueses, la corona de Castilla y la renta de Canarias: el caso de Antonio Rodríguez Lamego. In: IV Centenario del ataque de Van der Does a las Palmas de Gran Canaria (1999): Coloquio Internacional Canarias y el Atlántico, 1580-1648. Las Palmas de Gran Canaria, Espanha: Cabildo Insular de Gran Canaria, 2001. p. 609-626.

CARRASCO VÁZQUEZ, Jesús. Los conversos lusitanos y la Unión Ibérica: oportunidades y negocios. EI caso de Juan Núñez Correa. In: ALVAR EZQUERRA, Alfredo; CONTRERAS CONTRERAS, Jaime; RUIZ RODRÍGUEZ, José Ignacio (Ed.). Política y cultura en la época moderna (cambios dinásticos: milenarismos, mesianismos y utopías). Alcalá de Henares, Espanha: Universidad de Alcalá, 2004. p. 763-774.

CIORANESCU, Alejandro. Historia de Santa Cruz de Tenerife. Santa Cruz de Tenerife, Espanha: Caja General de Ahorros Santa Cruz de Tenerife, 1977.

COLLADO VILLALTA, Pedro. El embargo de bienes de los portugueses en la flota de Tierra Firme de 1641 (análisis de las irregularidades normalizadas y del poder lusitano en el comercio indiano de la época). Anuario de Estudios Americanos, Sevilla, n. 35, p. 169-207, 1979. 
CONTRERAS CONTRERAS, Jaime; GARCÍA GARCÍA, Bernardo José; PULIDO SERRANO, Juan Ignacio (Ed.). Familia, religión y negocio: el sefardismo en las relaciones entre el mundo ibérico y los Países Bajos en la Edad Moderna. Madrid: Fundación Carlos de Amberes, 2002.

DOMINGUEZ ORTIZ, Antonio. Los extranjeros en la vida española durante el siglo XVII. Sevilha, Espanha: Diputación de Sevilla, 1996 [1960].

EBBEN, Mauricio. Un triángulo imposible: la Corona española, el Santo Oficio y los banqueros portugueses, 1627-1655. Hispania, n. 184, p. 541-556, 1993.

EBBEN, Mauricio. Zilver, brood en kogels voor de Koning. Kredietverlening door Portugese bankiers aan de Spaanse Kron, 1621-1665 (Plata, pan y balas para el Rey. La financiación de los banqueros portugueses a la Monarquía española, 1621-1665). Leiden: Centrum voor Moderne Geschiedenis, Rijksuniversiteit Leiden, 1996.

ELLIOTT, John H. En búsqueda de la historia atlántica. Las Palmas de Gran Canaria, Espanha: Cabildo Insular de Gran Canaria, 2001.

FAJARDO SPÍNOLA, Francisco. Las conversiones protestantes en Canarias: siglos XVII y XVIII. Las Palmas de Gran Canaria, Espanha: Cabildo Insular de Gran Canaria, 1996.

FAJARDO SPÍNOLA, Francisco. Portugueses en Canarias en el siglo XVII. Una relación de 1626. XV Coloquio de Historia Canario-Americana (2002). Las Palmas de Gran Canaria, Espanha: Cabildo Insular de Gran Canaria, 2004. p. 310-320.

FERNÁNDEZ-ARMESTO, Felipe. Las Islas Canarias después de la conquista. La creación de una Sociedad Colonial a principios del siglo XVI. Las Palmas de Gran Canaria, , Espanha: Cabildo Insular de Gran Canaria, 1996 [1982].

GARCÍA FUENTES, Lutgardo. Licencias para la introducción de esclavos en Indias y envíos desde Sevilla en el siglo XVI. Jahrbuchfür Geschichte von Staat, Wirtschaftund Gesellschaft Lateinamerikas, n. 19, 1982. p. 1-46.

GUIMERÁ RAVINA, Agustín. Burguesía extranjera y comercio atlántico: la empresa comercial irlandesa en Canarias. Santa Cruz de Tenerife, Espanha: Gobierno de Canarias/CSIC, 1985.

GUIMERÁ RAVINA, Agustín; VIEIRA, Alberto. El sistema portuario-mercantil de las Islas del Atlántico Ibérico. História das Ilhas Atlánticas (Actas do IV Coloquio Internacional de História das Ilhas Atlánticas). Funchal, Portugal: Centro de Estudos de História do Atlântico, v. 1, 1996. p. 203-232.

LOBO CABRERA, Manuel. Gran Canaria y los contactos con las islas portuguesas atlánticas: Azores, Madera, Cabo Verde y Santo Tomé. V Coloquio de Historia Canario-Americana (1982). Las Palmas de Gran Canaria, Espanha: Cabildo Insular de Gran Canaria, 1985. p. 311-333.

LOBO CABRERA, Manuel. Los mercaderes franceses en Canarias en el siglo XVI. VI Coloquio de Historia Canario-Americana (1984). Las Palmas de Gran Canaria, Espanha: Cabildo Insular de Gran Canaria, 1987. p. 11-48.

LOBO CABRERA, Manuel. La Historia de las islas: Canarias y Madeira. II Coloquio Internacional de História da Madeira. Funchal, Portugal: Centro de Estudos de História do Atlântico, 1990. p. 531-546. 
LOBO CABERA, Manuel. Viajes y negocios entre La Palma y Cabo Verde. XII Coloquio Internacional Canarias y el Atlántico (1996). Las Palmas de Gran Canaria, Espanha: Cabildo Insular de Gran Canaria, 1998. p. 57-76.

LOBO CABRERA, Manuel; TORRES SANTA, Elisa. La Palma y Brasil: relaciones comerciales, 1600-1650. As Ilhas e o Brasil. Funchal, Portugal: Centro de Estudos de História do Atlântico, 2000. p. 171-195.

LÓPEZ BELINCHÓN, Bernardo José. Sacar la sustancia al reino. Comercio, contrabando y conversos portugueses, 1621-1640. Hispania, n. 209, p. 1017-1050, 2001.

LUXÁN MÉNDEZ, Santiago de. La revolución de 1640 en Portugal, sus fundamentos sociales y sus caracteres nacionales: El Consejo de Portugal, 1580-1640. Madrid: Universidad Complutense, 1988.

MARRERO RODRÍGUEZ, Manuela. Los genoveses en la colonización de Tenerife. Revista de Historia Canaria, La Laguna, n. 89, 1950. p. 52-65.

MATOS, Artur Teodoro de. Las relaciones de las Azores con la América española y las Canarias durante los siglos XVI y XVII. V Coloquio de Historia Canario-Americana (1982). Las Palmas de Gran Canaria, Espanha: Cabildo Insular de Gran Canaria, 1985. p. 723-745.

MORALES PADRÓN, Francisco. El comercio canario-americano (siglos XVI-XVIII). Sevilha, Espanha: Escuela de Estudios Hispano-Americanos, 1955.

MORALES PADRÓN, Francisco. Cedulario de Canarias. Sevilha, Espanha: Escuela de Estudios Hispanoamericanos, 1970.

OTTE, Enrique; RUÍZ-BARRUECOS Conchita. Los portugueses en la trata de esclavos negros de las postrimerías del siglo XVI. Moneda y Crédito, n. 85, p. 3-40, 1963.

PERAZA DE AYALA José. El régimen comercial de Canarias con las Indias en los siglos XVI, XVII y XVIII. Sevilha, Espanha: Publicaciones de la Universidad de Sevilla, 1977.

PÉREZ VIDAL, José. Aportación portuguesa a la población de Canarias. Datos para su contenido. Anuario de Estudios Atlánticos, Madrid/Las Palmas de Gran Canaria, n. 14, p. 41-106, 1968.

PÉREZ VIDAL, José. Los portugueses en Canarias. Las Palmas de Gran Canaria, Espanha: Cabildo Insular de Gran Canaria, 1991.

RUIZ RIVERA, Julián Bautista. Los portugueses y la trata negrera en Cartagena de Indias. Temas Americanistas, n. 15, p. 8-18, 2002.

RUMEU DE ARMAS, Antonio. Canarias y el Atlántico. Piraterías y ataques navales. Madrid: Gobierno de Canarias/Cabildos Insulares de Gran Canaria y Tenerife, 1991.

SERRA RÁFOLS, Elías. Discurso inaugural del año académico 1941-1942. Los portugueses en Canarias. La Laguna, Espanha: Imprenta Curbelo, 1941.

SERRANO MANGAS, Fernando. La encrucijada portuguesa: esplendor y quiebra de la Unión Ibérica en las Indias de Castilla (1600-1668). Badajoz, Espanha: Diputación de Badajoz, 2001.

TEJERA GASPAR, Antonio. Los libio-beréberes que poblaron las islas Canarias en la Antigüedad. In: TEJERA GASPAR, Antonio; CHÁVEZ ÁLVAREZ, María Esther; MONTESDEOCA, Marian (Ed.). Canarias y el África Antigua. La Laguna, Espanha: Centro de la Cultura Popular Canaria, 2006. p. 81-105. 
TORRES SANTANA, Elisa. Los azoreanos en las Canarias orientales. História das Ilhas Atlánticas (Actas do IV Coloquio Internacional de História das Ilhas Atlánticas). Funchal, Portugal: Centro de Estudos de História do Atlântico, v. 1, 1996. p. 287-301.

VALLADARES RAMÍREZ, Rafael. Felipe IV y la Restauración de Portugal. Málaga, Espanha: Algazara, 1994.

VALLADARES RAMÍREZ, Rafael. La Rebelión de Portugal: guerra, conflicto y poderes en la Monarquía Hispánica (1640-1680). Valladolid, Espanha: Consejería de Educación y Cultura, 1998.

VALLADARES RAMÍREZ, Rafael. Banqueros y vasallos: Felipe IV y el medio general (1630-1670). Cuenca, Equador: Universidad de Castilla-La Mancha, 2002.

VALLADARES RAMÍREZ, Rafael. Historia atlántica y ruptura ibérica, 1620-1680. Un ensayo bibliográfico. In: PARKER, Geoffrey (Ed.). La crisis de la monarquía de Felipe IV. Barcelona: Crítica, 2006. p. 327-350.

VERLINDEN, Charles. Castellanos, portugueses, italianos y otros pobladores de Canarias a raíz de la conquista. Una cuestión de proporciones. VI Coloquio de Historia Canario-Americana (1984). Las Palmas de Gran Canaria, Espanha: Cabildo Insular de Gran Canaria, 1987. p. 11-23.

VIEIRA, Alberto. O comércio de cereais das Canárias para a Madéira nos séculos XVI-XVII. VI Coloquio de Historia Canario-Americana (1984). Las Palmas de Gran Canaria, Espanha; Cabildo Insular de Gran Canaria, 1987. p. 325-351.

VIEIRA, Alberto. As conexôes canario-madeirenses nos sécalos XV al XVIII. VIII Coloquio de Historia Canario-Americana (1988). Las Palmas de Gran Canaria, Espanha: Cabildo Insular de Gran Canaria, 1991. p. 865-917.

VIEIRA, Alberto. Portugal y las islas del Atlántico. Madrid: Mapfre, 1992.

VIEIRA, Alberto. Las Islas y el mundo atlántico. 1580-1648. IV Centenario del ataque de Van der Does a las Palmas de Gran Canaria (1999): Coloquio Internacional Canarias y el Atlántico, 1580-1648. Las Palmas de Gran Canaria, Espanha: Cabildo Insular de Gran Canaria, 2001. p. 309-347.

VIEIRA, Alberto. The Fortune of Fortunates. The Islands and the Atlantic System. In: PIETSCHMANN, Horst (Ed.). Atlantic History. History of the Atlantic System. 1580-1830. Göttingen, Alemanha: Vandenhoeck \& Ruprecht, 2002. p. 199-247.

VIEIRA, Alberto. As ilhas atlánticas para una visao dinâmica da sua história. Anuario de Estudios Atlánticos, Madrid/Las Palmas de Gran Canaria, n. 50, 2004. p. 219-264.

VILA VILAR, Enriqueta. Las Canarias como base de aprovisionamiento de navíos portugueses. II Coloquio de Historia Canario-Americana (1977). Las Palmas de Gran Canaria, Espanha: Cabildo Insular de Gran Canaria, 1978. p. 286-287.

VILA VILAR, Enriqueta. Los asientos portugueses y el contrabando de negros. Anuario de Estudios Americanos, Sevilla, n. 30, 1979. p. 557-599.

VIÑA BRITO, Ana. Las relaciones Canarias-Brasil antes de la Unión de los Reinos Ibéricos. Politeia: história e sociedade, n. 1, v. 7, p. 143-161, 2007. 